\title{
Caracterización de sistemas productivos lecheros en el Sur de Chile con distintos sistemas de manejo y su relación con el recuento total bacteriano de la leche producida: un análisis multivariable
}

\author{
Characterisation of milk production systems of Southern Chile under different farm management \\ systems and their relationship with total bacterial count of milk: a multivariate analysis \\ BL Carrillo ${ }^{a^{*}}$, C Pinargote ${ }^{\mathrm{a}}$, C Brito ${ }^{\mathrm{a}}$, J González ${ }^{\mathrm{a}}$, VH Moreira ${ }^{\mathrm{b}}$, A Báez \\ ${ }^{a}$ Instituto de Ciencia y Tecnología de los Alimentos, Universidad Austral de Chile, Valdivia, Chile.

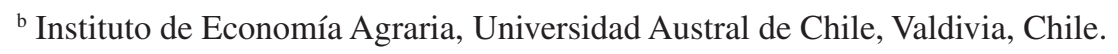

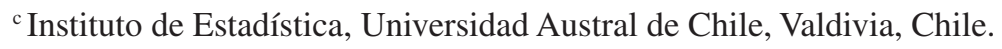

\begin{abstract}
SUMMARY
In this study, different types of dairy management systems for milk production (SP) in Southern Chile were determined and characterised, relating management variables to bacterial count in raw milk. Qualitative information on several management variables was utilised for evaluation. A survey was conducted on 108 dairy farmers and the management systems were evaluated using both multiple correspondence and conglomerate analysis. Four milk production systems were identified. The SP1 group (43\% of the surveyed farmers) that delivered $87 \%$ of the industry milk had an adequate production management, with $100 \%$ of the produced milk being classified as best quality $(\leq 20.000 \mathrm{cfu} / \mathrm{mL})$. The SP2 group (20\% of surveyed farmers) that produced $10 \%$ of the total milk delivered, mainly showed inadequate ways of milk production, however, $77 \%$ of the milk was classified as best quality. The uneven results suggest that further in-depth analysis of the group is required. Finally, the SP3 and SP4 groups that produced only $3 \%$ of the milk delivered but represented $37 \%$ of the surveyed farmers, had inadequate production management and were classified as "problem groups" with low milk quality with bacterial counts $>200.000 \mathrm{cfu} / \mathrm{mL}$ for $76 \%$ and $72 \%$ of the produced milk, respectively; specially the SP3 group with $61 \%$ of the milk in the worst quality category (> $800.000 \mathrm{cfu} / \mathrm{mL}$ ). Therefore, corrective actions, mainly related to milk storage temperature and milking equipment cleaning, are required for the SP3 and SP4 groups.
\end{abstract}

Key words: dairy producers, management systems, bacterial counts, multivariate analysis.

\section{RESUMEN}

Este estudio determinó y caracterizó tipos de sistemas productivos lecheros para obtención de leche (SP) en el Sur de Chile, asociando las variables de manejo con recuentos bacterianos de las partidas de leche de éstos. Se utilizó información cualitativa referente a diversas variables de manejo para producir leche. Se analizaron 108 productores, mediante análisis de correspondencias múltiples y análisis de conglomerados. Se identificó 4 formas de obtener leche. El grupo SP1 (43\% de la muestra) aportó el $87 \%$ de la leche a la industria y presentó adecuadas formas de manejo, clasificando todos, el $100 \%$ de sus partidas de leche en el mejor rango de calidad $(\leq 20.000 \mathrm{ufc} / \mathrm{mL})$. El SP2 (20\% de la muestra) aportó un $10 \%$ del total de leche aunque mayoritariamente presentó inadecuadas formas de manejo, y clasificó un $77 \%$ de las partidas de leche en el mejor rango de calidad $(\leq 20.000$ $\mathrm{ufc} / \mathrm{mL}$ ), esta inconsistencia sugiere la necesidad de analizar en mayor profundidad este grupo. Finalmente, los grupos SP3 y SP4, que en conjunto entregaron sólo un 3\% de la leche de la muestra total a la industria pero que representaron un $37 \%$ de la muestra, presentaron inadecuadas formas de manejo y se consideraron "grupos problema", predominando en ambos partidas de leche de mala calidad con recuentos $>200.000 \mathrm{ufc} / \mathrm{mL}$ en un 76 y $72 \%$, respectivamente, en especial en SP3 con un $61 \%$ de las partidas de leche clasificadas en el peor rango establecido (> $800.000 \mathrm{ufc} / \mathrm{mL}$ ). Consecuentemente se deben realizar acciones correctivas, relacionadas fundamentalmente con la temperatura de almacenamiento de la leche y con el correcto lavado de equipos, estanques y utensilios en SP3 y SP4.

Palabras claves: productores lecheros, sistemas de manejo, recuentos bacterianos, análisis multivariable.

\section{INTRODUCCIÓN}

La calidad microbiológica de la leche cruda, es uno de los requisitos más importantes para la industria láctea.

Aceptado: 03.10.2013.

* Casilla 567, Facultad de Ciencias Agrarias, Universidad Austral de Chile, Valdivia, Chile; bcarrill@uach.cl
Elevados recuentos bacterianos pueden incidir negativamente en el procesamiento industrial, y hacer disminuir tanto la vida útil como la calidad organoléptica y la calidad nutricional de los productos elaborados (Revelli y col 2004, Godic y Golc 2008, Mattos y col 2010).

Es por ello que la industria láctea ha implementado desde el año 1995 sistemas de pago o compra de leche diferenciados según los recuentos bacterianos de ésta, 
entre otros parámetros. Anteriormente la compra de leche a productores estuvo regulada por el Decreto 271, en el cual se estableció por primera vez en Chile un sistema de clasificación (Carrillo y Vidal 2002). Lo anterior, ha permitido mejorar la calidad de la leche recepcionada en planta mediante incentivos económicos (bonificaciones al precio base) y programas de mejoramiento.

A nivel predial la calidad microbiológica está determinada por múltiples variables de manejo que interactúan en forma simultánea. Dicha combinación de variables establecen diferentes formas de producir leche, generando la existencia de sistemas productivos heterogéneos y contrastantes. En una primera etapa es importante establecer cuáles son los tipos de sistemas de manejo o producción de leche que coexisten en una determinada zona o región, con el objetivo de llegar a establecer acciones de intervención o proponer estrategias que permitan mejorar los aspectos relacionados con su desarrollo (Avilez y col 2010).

El objetivo de este estudio fue establecer y caracterizar los distintos tipos de sistemas de manejo y obtención de leche existentes en el sur de Chile, mediante la aplicación de análisis estadístico multivariable, y determinar cómo estos manejos a nivel predial se relacionan con la calidad bacteriana de la leche obtenida.

\section{MATERIAL Y MÉTODOS}

\section{SELECCIÓN DE LA MUESTRA Y RECOLECCIÓN DE INFORMACIÓN}

El universo de productores lecheros corresponde al total de proveedores que entregan su leche a una empresa procesadora del sur de Chile. La muestra de productores corresponde a 108 casos, los que a su vez conforman el $16 \%$ del universo en estudio y que en conjunto aportan el $15 \%$ de la leche que recibe dicha industria láctea. La muestra fue obtenida mediante la "Estimación y determinación del tamaño de la muestra para poblaciones finitas" (Berenson y Levine 1992). Todos los predios del estudio se ubican entre las comunas de Máfil (Región de los Ríos) y Osorno (Región de los Lagos). La selección de los encuestados se realizó de manera proporcional (muestreo estratificado) a los diferentes rangos de recuentos bacterianos que establece esta industria láctea como esquema de pago ( $\leq 20.000 \mathrm{ufc} / \mathrm{mL} ; 20.001-50.000 \mathrm{ufc} / \mathrm{mL} ; 50.001$ - $200.000 \mathrm{ufc} / \mathrm{mL} ; 200.001$ - $400.000 \mathrm{ufc} / \mathrm{mL} ; 400.001$ $800.000 \mathrm{ufc} / \mathrm{mL}$ y $>800.000 \mathrm{ufc} / \mathrm{mL}$ ), información que fue proporcionada por la empresa láctea. La información abarcó los recuentos bacterianos de 64 análisis quincenales para cada productor, entre enero de 2007 y agosto de 2009, con el fin de obtener la muestra en estudio.

De acuerdo a la metodología establecida por Hernández y col (1998), y considerando parámetros utilizados en otros estudios (Rasmussen y col 2002, Ayadi y col 2003, Reinemann y col 2005, Stull y col 2005, Hoe y Ruegg 2006), se diseñó una pauta de evaluación que consideró preguntas de tipo cerradas y con alternativas delimitadas, la cual sirvió para recolectar información cualitativa a nivel predial sobre el comportamiento de las diferentes variables de manejo para la obtención de leche. Dicha pauta fue aplicada entre octubre y noviembre de 2009 (45 días), periodo en el que generalmente se alcanza la máxima producción de leche a nivel predial en la zona sur de Chile. Esta encuesta (diseñada en el estudio de Pinargote 2009), fue aplicada a través de una entrevista en el predio al encargado del proceso de ordeña. Además, se contó con los recuentos bacterianos de las tres últimas quincenas para el mismo período en que se aplicó la encuesta, a objeto de hacer coincidir dichos recuentos con el comportamiento de las variables de manejo para ese momento, datos que finalmente fueron utilizados para los análisis estadísticos del presente estudio (caracterización).

\section{ANÁLISIS ESTADÍSTICO MULTIVARIABLE}

A partir del conjunto de variables obtenidas con la aplicación de la pauta de evaluación, el análisis estadístico permitió seleccionar las 21 variables de manejo que mejor discriminaban entre productores para la determinación y caracterización de sistemas productivos (variables activas) que permitieron obtener los diferentes sistemas productivos caracterizados en este estudio. El listado de variables fue: $\mathrm{REC}=$ Forma de recolección; $\mathrm{T}^{\circ} \mathrm{REC}=\mathrm{T}^{\circ}$ de recolección $4-6^{\circ} \mathrm{C} ;$ FREC $=$ Frecuencia de recolección; LEU = Limpieza equipos/utensilios de ordeño; LML = Línea/manguera de leche limpias; VAS = Vaso de leche limpio; ADO = Empleo agua caliente $(70-$ $75^{\circ} \mathrm{C}$ ) en lavado equipos/utensilios de ordeño con detergente alcalino clorado; $\mathrm{ADE}=$ Empleo de agua caliente (70-75 ${ }^{\circ} \mathrm{C}$ ) en lavado del estanque con detergente alcalino clorado; tDO = Lavado equipos/utensilios de ordeño con detergente alcalino clorado es entre 8-10 min.; tDE $=$ Lavado del estanque con detergente alcalino clorado es entre 8-10 min; $\mathrm{T}^{\circ} \mathrm{SO}=\mathrm{T}^{\circ}$ salida del agua con detergente en el equipo de ordeño es entre $40-45^{\circ} \mathrm{C}$ después de 8-10 min.; $\mathrm{T}^{\circ} \mathrm{SE}=\mathrm{T}^{\circ}$ salida del agua con detergente en el estanque es entre $40-45^{\circ} \mathrm{C}$ después de los 8-10 min.; $\mathrm{LAO}=$ Lavado con solución ácida en equipo de ordeño se emplea según las recomendaciones del fabricante $\left(\mathrm{T}^{\circ}\right)$; tRO $=$ Tiempo de recirculación del lavado con ácido en el equipo de ordeño es de 8-10 min.; tRE = Tiempo de recirculación del lavado con ácido en el estanque es de 8-10 min.; LUB = Lavado de ubres; PEZ = Pezoneras rugosas al tacto o rotas; $\mathrm{PRO}=$ Protocolos para lavado de equipos de ordeño, utensilios y/o estanque; CAP = Capacitación ordeñador (último año).

Se empleó en conjunto dos técnicas multivariantes exploratorias (Hair y col 1999, Vivanco 1999): análisis de correspondencias múltiples (ACM) y análisis de conglomerados (AC).

El ACM estudia la relación existente entre múltiples variables cualitativas, donde cada pregunta constituye 
una variable, cuyas categorías son las respuestas propuestas, entre las cuales se debe elegir una, y que son representadas (por puntos) en un espacio gráfico matemático (mapa perceptual), permitiendo su rápida interpretación (Escofier y Pagès 1992, Vivanco 1999, Bécue 2002).

ElAC permite conformar grupos, en términos de las variables empleadas para su clasificación (Hair y col 1999). Debido a la naturaleza no numérica de las variables, el AC se realizó a partir de las coordenadas generadas por el ACM que reunieron un $80 \%$ de la información original (Bécue 2002). Se utilizó como algoritmo de agrupación el método de Ward (agrupación ascendente jerárquica), y como medida de disimilitud la distancia euclídea (Hair y col 1999). El tratamiento estadístico de los datos se efectuó por medio del software XLSTAT (Addinsoft, New York, UnitedStates, 2009).

Por medio del AC se establecieron cuatro sistemas productivos lecheros y por medio de la ACM se realizó la descripción para cada grupo. Según Garnica (1998), en un ACM, categorías "cercanas" al origen de coordenadas $(0,0)$ indica características escogidas por la mayoría de las observaciones y así caracterizan al grupo, más aún si se encuentran en dicho origen, esa característica se encuentra presente en todas las observaciones, mientras que categorías "muy alejadas" del origen indica que éstas se encuentran con poca frecuencia. Además, categorías "cercanas entre sî" indica que dichas características aparecen correlacionadas, donde dicha correlación es "más inten- sa" cuanto "más alejados" estén del origen (Escofier y col 1992). De esta forma se establecieron cuatro sistemas productivos lecheros.

\section{RESULTADOS}

\section{SISTEMA PRODUCTIVO 1 (SP1) (43\% DE LA MUESTRA)}

Este sistema está formado por productores con ordeño mecánico y con estanque de frío para almacenar la leche. Este grupo aportó el $87 \%$ de la leche que la muestra de productores vendió a la industria láctea, y su principal característica es que el 100\% de los predios clasificó los recuentos bacterianos de leche en el mejor rango de cali$\mathrm{dad}(\leq 20.000 \mathrm{ufc} / \mathrm{mL})$ (cuadro 1$)$.

De acuerdo al ACM (figura 1), se observó que el SP1 es "altamente homogéneo" para producir leche lo que se refleja en su baja dispersión de variables. Este grupo se caracteriza porque los predios mantienen la leche refrigerada entre $4-6^{\circ} \mathrm{C}\left(\mathrm{T}^{\circ} \mathrm{REC} 100 \%\right)$, a la espera de ser recolectada por un camión cisterna (REC igual a 100\%), $y$ en forma diaria (FREC 91\%).

La limpieza de equipos de ordeño y estanque de frío se realiza en forma automática o semiautomática ("Clean-inPlace") (LEU100\%), utilizando para ello detergente alcalino clorado y solución ácida, cumpliendo además, con los requisitos recomendados de temperatura y tiempo de aplicación necesarios para una correcta limpieza $\left(70-75^{\circ} \mathrm{C}\right.$

Cuadro 1. Distribución porcentual de las frecuencias de los distintos recuentos bacterianos de la leche por grupo o sistema productivo existente.

Percentage distribution of the frequencies of the different milk microbiological counts by group or production system.

\begin{tabular}{|c|c|c|c|c|}
\hline \multirow[b]{3}{*}{ Recuentos bacterianos $(\mathrm{ufc} / \mathrm{mL})^{\mathrm{d}}$} & \multicolumn{4}{|c|}{ Sistema Productivo } \\
\hline & $\mathrm{SP}^{\mathrm{a}}$ & $\mathrm{SP}^{\mathrm{a}}$ & $\mathrm{SP}^{\mathrm{b}}$ & $\mathrm{SP}^{\mathrm{c}}$ \\
\hline & $\%$ & $\%$ & $\%$ & $\%$ \\
\hline \multicolumn{5}{|l|}{ Bonificación económica (al precio base) } \\
\hline$\leq 20.000$ & 100 & 77 & 0 & 14 \\
\hline $20.001-50.000$ & 0 & 0 & 12 & 7 \\
\hline $50.001-200.000$ & 0 & 9 & 12 & 7 \\
\hline \multicolumn{5}{|l|}{ Descuento económico (al precio base) } \\
\hline $200.001-400.000$ & 0 & 14 & 3 & 14 \\
\hline $400.001-800.000$ & 0 & 0 & 12 & 29 \\
\hline$>800.000$ & 0 & 0 & 61 & 29 \\
\hline Volumen leche entregado a la industria (\%) & 87 & 10 & 2 & 1 \\
\hline Productores (\% del total de la muestra que pertenecen al grupo) & 43 & 20 & 24 & 13 \\
\hline
\end{tabular}

${ }^{a}$ Productores con ordeño mecánico y con estanque de almacenamiento de leche $\left(4-6^{\circ} \mathrm{C}\right)$.

${ }^{\mathrm{b}}$ Productores con ordeño mecánico y sin estanque de almacenamiento de leche (tarro).

${ }^{\mathrm{c}}$ Productores con ordeño manual y sin estanque de almacenamiento de leche (tarro).

${ }^{\mathrm{d}}$ De acuerdo a la media geométrica de 3 análisis quincenales (durante la visita a productores). 


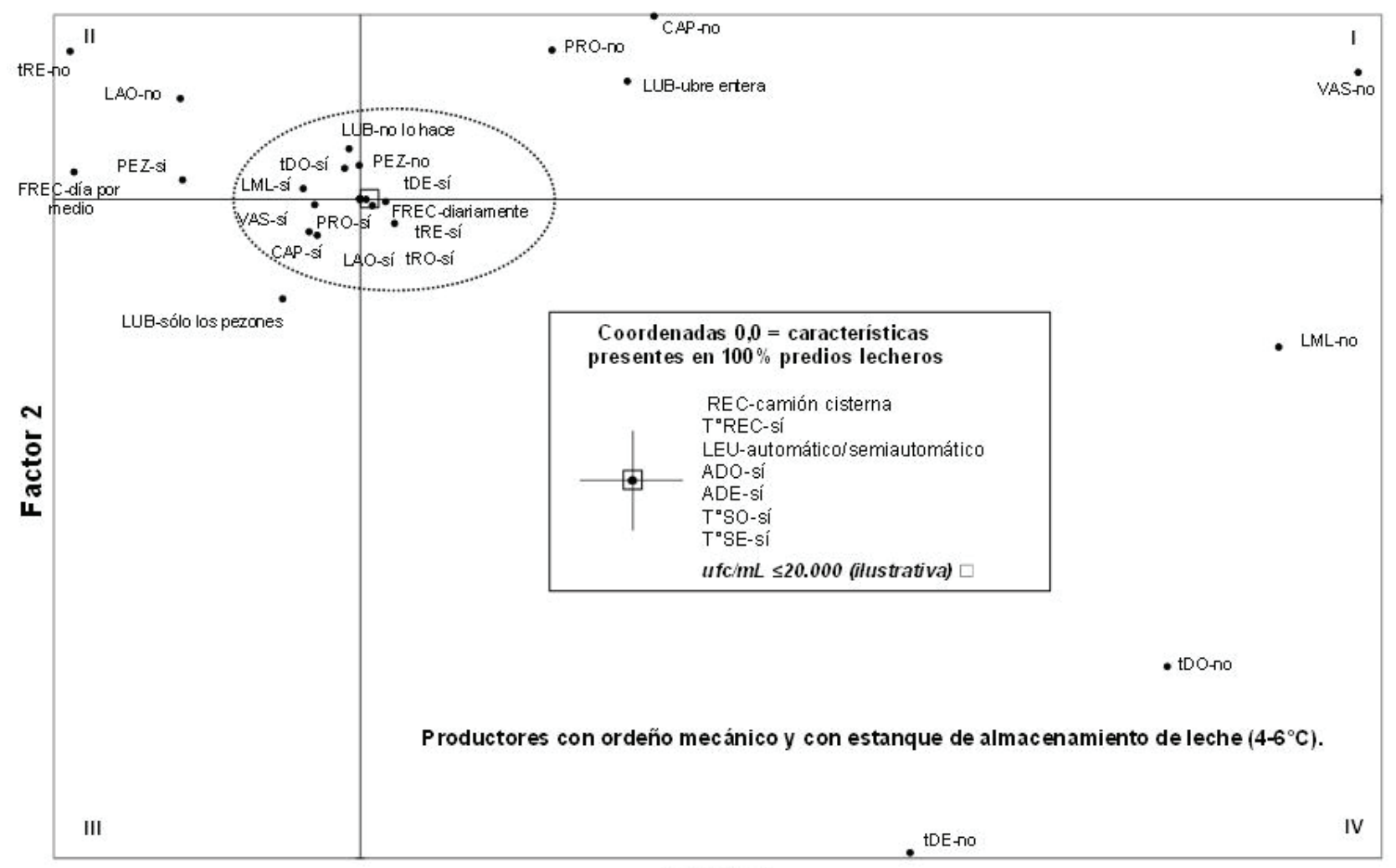

\section{Factor 1}

- Variables activas (categorias) $\square$ Variable ilustrativa (categorias)

Figura 1. Análisis de correspondencias múltiples, primer plano factorial SP1.

Multiple Correspondence Analysis, first factorial plane SP1.

REC $=$ Forma recolección; $\mathrm{T}^{\circ} \mathrm{REC}=\mathrm{T}^{\circ}$ recolección $4-6^{\circ} \mathrm{C} ; \mathrm{FREC}=$ Frecuencia recolección; LEU $=$ Limpieza equipos/utensilios de ordeño; LML $=$ Línea/manguera de leche limpias; VAS = Vaso de leche limpio; ADO = Empleo agua caliente $\left(70-75^{\circ} \mathrm{C}\right)$ en lavado equipos/utensilios de ordeño con detergente alcalino clorado; $\mathrm{ADE}=$ Empleo de agua caliente $\left(70-75^{\circ} \mathrm{C}\right)$ en lavado del estanque con detergente alcalino clorado; $\mathrm{tDO}=\mathrm{Lavado}$ equipos/ utensilios de ordeño con detergente alcalino clorado es entre 8 - 10 min.; tDE = Lavado del estanque con detergente alcalino clorado es entre 8-10 min; $\mathrm{T}^{\circ} \mathrm{SO}=\mathrm{T}^{\circ}$ salida del agua con detergente en el equipo de ordeño es entre $40-45^{\circ} \mathrm{C}$ después de 8-10 min.; $\mathrm{T}^{\circ} \mathrm{SE}=\mathrm{T}^{\circ}$ salida del agua con detergente en el estanque es entre $40-45^{\circ} \mathrm{C}$ después de los 8-10 min.; LAO = Lavado con solución ácida en equipo de ordeño se emplea según las recomendaciones del fabricante $\left(\mathrm{T}^{\circ}\right)$; tRO = Tiempo de recirculación del lavado con ácido en el equipo de ordeño es de 8-10 min.; tRE = Tiempo de recirculación del lavado con ácido en el estanque es de 8-10 min.; LUB = Lavado de ubres; PEZ = Pezoneras rugosas al tacto o rotas; PRO = Protocolos para lavado de equipos de ordeño, utensilios y/o estanque; CAP = Capacitación ordeñador (último año).

durante 10 minutos), según señala Keown y Kononoff (2006) ADO-sí 100\%; ADE-sí100\%; Tº SO-sí 100\%; T'SE-sí 100\%; tRO-sí100\%;tRE-sí 96\%; tDO-sí 96\%, tDE-sí 98\%; LAO-sí 80\%). A consecuencia de lo anterior, la línea y manguera de leche (LML 96\%) y el vaso de leche o unidad final (VAS93\%) se encontraban limpios.

\section{SISTEMA PRODUCTIVO 2 (SP2) (20\% DE LA MUESTRA)}

Corresponden a este grupo productores con ordeño mecánico y con estanque de frío para almacenar la leche, y que aportaron el 10\% del total de la leche que la muestra de productores vendió a la industria. En este grupo el $77 \%$ de las partidas de leche estuvo dentro del mejor rango establecido por la industria $(\leq 20.000 \mathrm{ufc} / \mathrm{mL})$, y sólo un $14 \%$ de éstas estuvo sujeta a descuento económico por clasificar en el rango de 200.001-400.000 ufc/ $\mathrm{mL}$ (cuadro 1).

Grupo un tanto "heterogéneo" para obtener leche a nivel predial (figura 2). Si bien en todos los predios la leche era mantenida entre $4-6^{\circ} \mathrm{C}\left(\mathrm{T}^{\circ} \mathrm{REC} 100 \%\right)$, a la espera del retiro por el camión cisterna (REC 100\%), y la limpieza de equipos de ordeño y estanques de frío principalmente era automatizada o semiautomatizada (LEU 75\%), se pudo constatar que en general y en la mayoría de los casos no se realizaban "adecuadas prácticas de manejo". Así, por ejemplo, la temperatura y tiempo en el lavado (equipos ordeño, estanque) en la mayoría de los predios fue inferior a la recomendada (menos de $70{ }^{\circ} \mathrm{C}$ por un tiempo inferior a 10 minutos) considerando lo señalado 


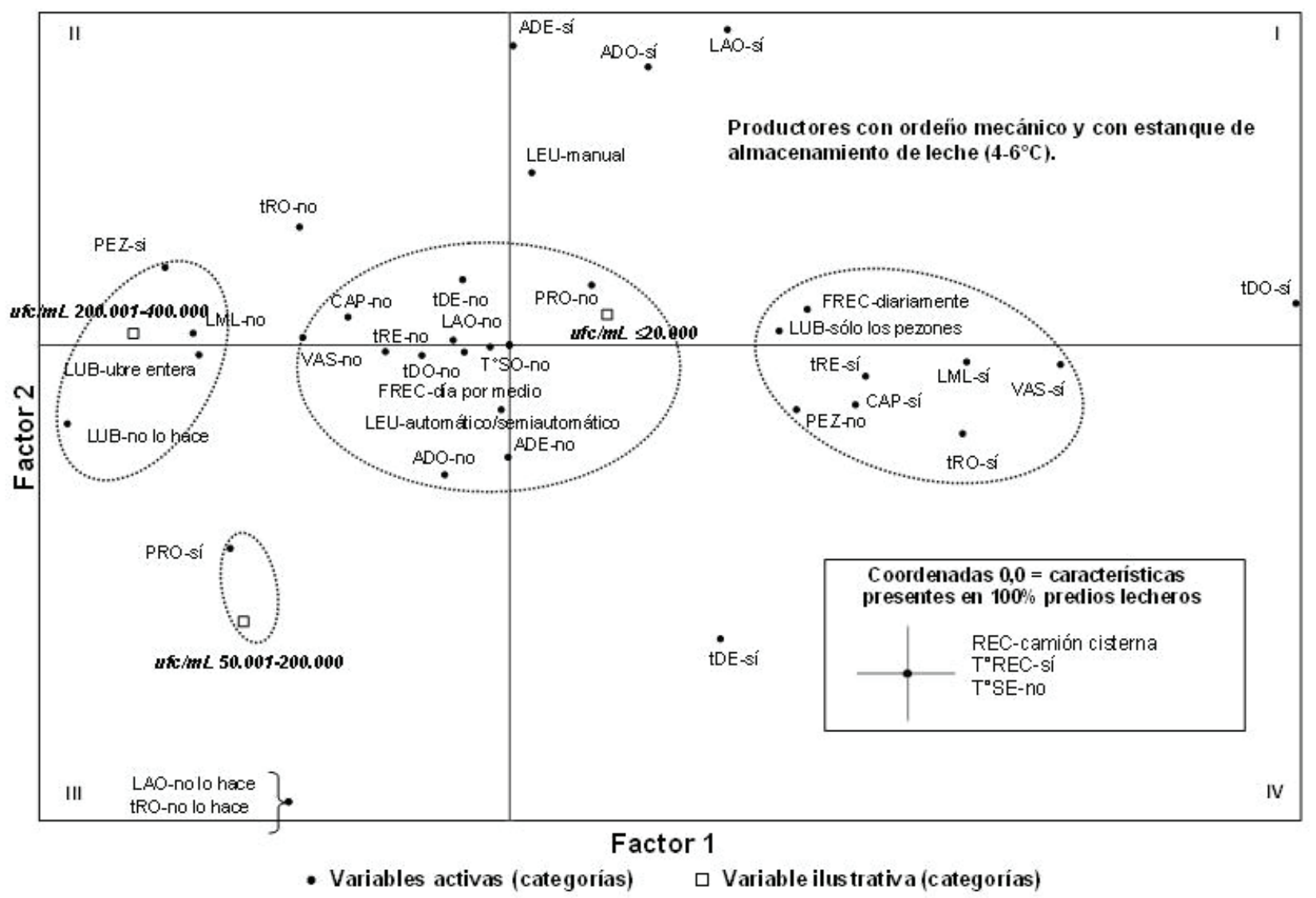

Figura 2. Análisis de correspondencias múltiples, primer plano factorial SP2. Multiple Correspondence Analysis, first factorial plane Group SP2.

$\mathrm{REC}=$ Forma recolección; $\mathrm{T}^{\circ} \mathrm{REC}=\mathrm{T}^{\circ}$ recolección $4-6^{\circ} \mathrm{C} ; \mathrm{FREC}=$ Frecuencia recolección $; \mathrm{LEU}=$ Limpieza equipos/utensilios de ordeño; $\mathrm{LML}=$ Línea/manguera de leche limpias; VAS = Vaso de leche limpio; $\mathrm{ADO}=$ Empleo agua caliente $\left(70-75^{\circ} \mathrm{C}\right)$ en lavado equipos/utensilios de ordeño con detergente alcalino clorado; $\mathrm{ADE}=$ Empleo de agua caliente $\left(70-75^{\circ} \mathrm{C}\right)$ en lavado del estanque con detergente alcalino clorado; tDO $=\mathrm{Lavado}$ equipos $/$ utensilios de ordeño con detergente alcalino clorado es entre 8-10 min.; tDE = Lavado del estanque con detergente alcalino clorado es entre 8 - 10 min; $\mathrm{T}^{\circ} \mathrm{SO}=\mathrm{T}^{\circ}$ salida del agua con detergente en el equipo de ordeño es entre $40-45^{\circ} \mathrm{C}$ después de $8-10 \mathrm{~min} . ; \mathrm{T}^{\circ} \mathrm{SE}=\mathrm{T}^{\circ}$ salida del agua con detergente en el estanque es entre $40-45^{\circ} \mathrm{C}$ después de los 8 - 10 min.; $\mathrm{LAO}=$ Lavado con solución ácida en equipo de ordeño se emplea según las recomendaciones del fabricante $\left(\mathrm{T}^{\circ}\right)$; tRO = Tiempo de recirculación del lavado con ácido en el equipo de ordeño es de 8 - 10 min.; tRE = Tiempo de recirculación del lavado con ácido en el estanque es de 8 - 10 min.; LUB = Lavado de ubres; PEZ = Pezoneras rugosas al tacto o rotas; PRO = Protocolos para lavado de equipos de ordeño, utensilios y/o estanque; $\mathrm{CAP}=$ Capacitación ordeñador (último año).

por Keown y Kononoff (2006) (ADO-no 68\%; ADE-no 73\%; T ${ }^{\circ}$ SO-no $95 \%$; $\mathrm{T}^{\circ}$ SE-no $100 \%$; tDO-no $86 \%$; tDEno $82 \%$; LAO-no $77 \%$; tRO-no $60 \%$; tRE-no $86 \%$ ), encontrándose principalmente sucios los equipos, al igual que la línea y manguera de leche (LML 60\%) y el vaso de leche (VAS 73\%).

\section{SISTEMA PRODUCTIVO 3 (SP3) (24\% DE LA MUESTRA)}

Pertenecen a este grupo productores con menor nivel tecnológico que los anteriores. Con ordeño mecánico pero sin estanque de frío para almacenar la leche (sin línea de leche, el ordeño es directo a tarro), pese a constituir el 24\% de la muestra, sólo aportaron el 2\% de la leche vendida. Este grupo presentó mayoritariamente
(76\%) recuentos bacterianos sujetos a descuento económico (> $200.000 \mathrm{ufc} / \mathrm{mL}$ ), en especial aquellos que clasificaron sus partidas de leche en el peor rango de calidad (> $800.000 \mathrm{ufc} / \mathrm{mL} ; 61 \%$ de los predios) (cuadro 1 ).

De acuerdo a la figura 3 se pudo constatar que mayoritariamente tampoco realizaban "adecuadas prácticas de manejo"; por ejemplo, no se cumplía con la temperatura ni con el tiempo de lavado de equipos y utensilios, considerando los valores indicados anteriormente $\left(70-75^{\circ} \mathrm{C}\right.$ durante 10 minutos). En el 100\% de los predios la leche era recolectada en tarros de aluminio (REC), sin enfriar ( $\left.\mathrm{T}^{\circ} \mathrm{REC}\right)$.

Este grupo (cuadrantes II-III) se caracterizó por realizar la limpieza de los equipos de ordeño (LEU) en forma manual (85\%) y sin cumplir con el tiempo adecuado para el lavado, en la mayoría de los casos, el que además fue 


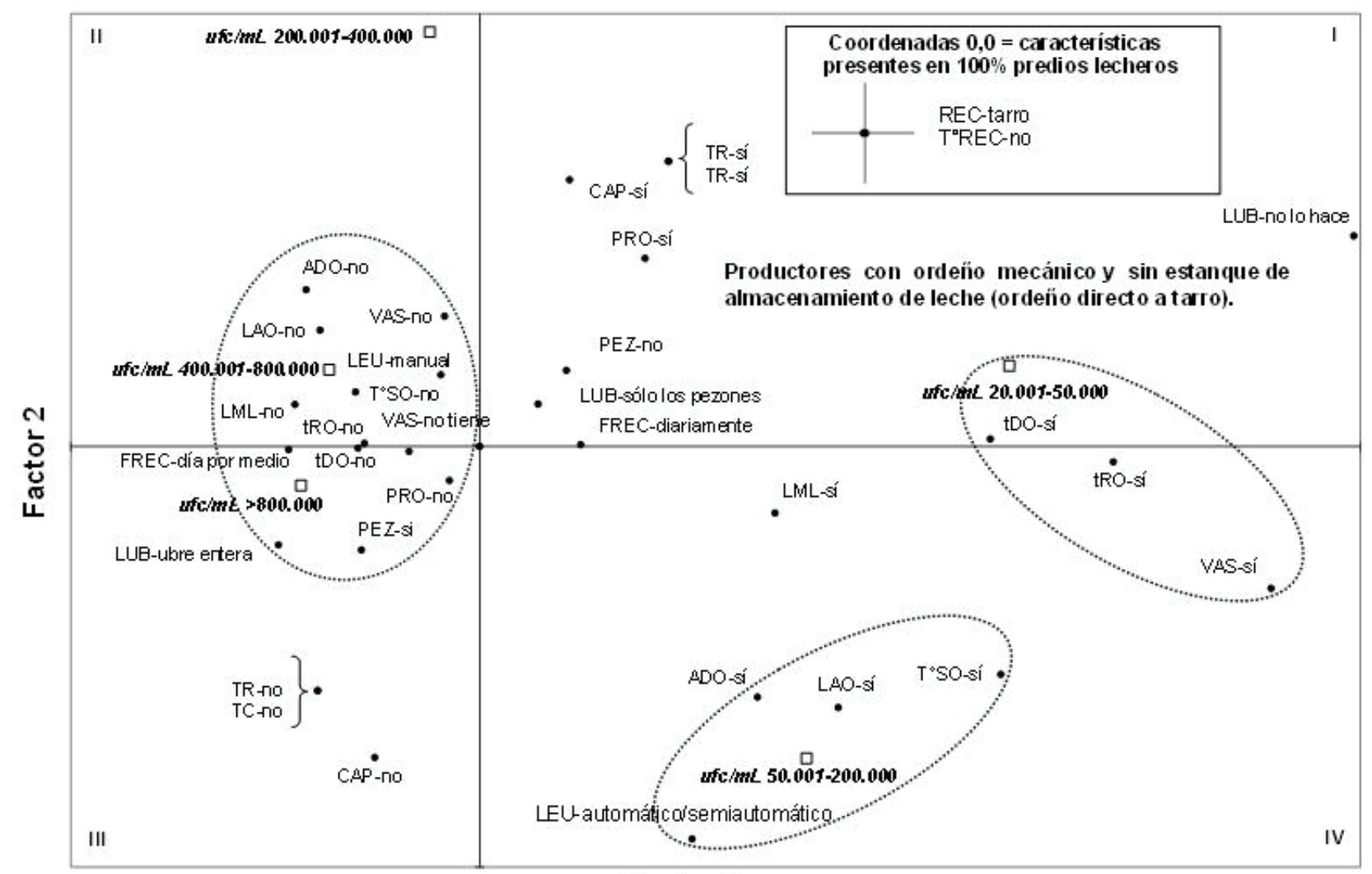

Factor 1

- Variables activas (categorias)

$\square$ Variable ilustrativa (categorías)

Figura 3. Análisis de correspondencias múltiples, primer plano factorial SP3.

Multiple Correspondence Analysis, first factorial plane Group SP3.

REC $=$ Forma recolección; $\mathrm{T}^{\circ} \mathrm{REC}=\mathrm{T}^{\circ}$ recolección $4-6^{\circ} \mathrm{C} ; \mathrm{FREC}=$ Frecuencia recolección; LEU $=$ Limpieza de equipos/utensilios de ordeño; LML = Línea/manguera de leche limpias; VAS = Vaso de leche limpio; $\mathrm{ADO}=$ Empleo agua caliente $\left(70-75^{\circ} \mathrm{C}\right)$ en lavado equipos/utensilios de ordeño con detergente alcalino clorado; $\mathrm{tDO}=$ Lavado equipos/utensilios de ordeño con detergente alcalino clorado es entre 8 - 10 min.; $\mathrm{T}^{\circ} \mathrm{SO}=\mathrm{T}^{\circ}$ salida del agua con detergente en el equipo de ordeño es entre $40-45^{\circ} \mathrm{C}$ después de 8 - 10 min.; LAO = Lavado con solución ácida en equipo de ordeño se emplea según las recomendaciones del fabricante $\left(\mathrm{T}^{\circ}\right)$; tRO = Tiempo de recirculación del lavado con ácido en el equipo de ordeño es de 8-10 min.; LUB = Lavado de ubres; PEZ = Pezoneras rugosas al tacto o rotas; TR = Tarros en rejillas o colgados boca abajo, sobre el nivel del suelo; $\mathrm{TC}=\mathrm{Se}$ filtra la leche en los tarros; PRO = Protocolos para lavado de equipos de ordeño, utensilios y/o estanque; CAP = Capacitación ordeñador (último año).

difícil de controlar (ADO-no 62\%; T ${ }^{\circ} \mathrm{O}-$ no $81 \%$; tDOno $81 \%$; LAO-no 70\%; tRO-no 85\%). La mayoría de los predios $(81 \%)$ no contaban con vaso de leche (VAS) y cuando éste estaba presente se encontraba sucio. Las pezoneras (PEZ) en la mitad de los predios se encontraron rugosas y sucias, producto de un uso por un tiempo excesivo superior al recomendado (máximo 2.500 ordeños). Además, este grupo también se caracterizó por un manejo inadecuado de los pezones, es decir, lavado de toda la ubre quedando restos de agua en los pezones, los que no fueron secados con toalla de papel desechable (LUBubre entera), y la no existencia de protocolos (PRO) para el lavado de equipos y utensilios (85\%). Lo anterior fue asociado a altos recuentos bacterianos (400.001-800.000; $>800.000 \mathrm{ufc} / \mathrm{mL}$ ).

\section{SISTEMA PRODUCTIVO 4 (SP4) (13\% DE LA MUESTRA)}

En este grupo se observó que la mayoría de los productores tenían un menor nivel tecnológico. Ordeñaban a mano y almacenaban la leche en tarros. Sólo aportaban el $1 \%$ de la leche recepcionada en la industria láctea. $\mathrm{Al}$ igual que SP3, los predios mayoritariamente (72\%) clasificaron su leche en el rango sometido a descuentos (> $200.000 \mathrm{ufc} / \mathrm{mL}$ ) (cuadro 1), por lo cual también fue considerado "grupo problema".

De acuerdo a la figura 4 en el $100 \%$ de los predios la leche era recolectada en tarros de aluminio (REC), a temperatura ambiente $\left(\mathrm{T}^{\circ} \mathrm{REC}\right)$. Al emplear solamente utensilios para la ordeña (tarros, jarros, baldes), la limpieza era realizada manualmente (LEU), y ningún productor 


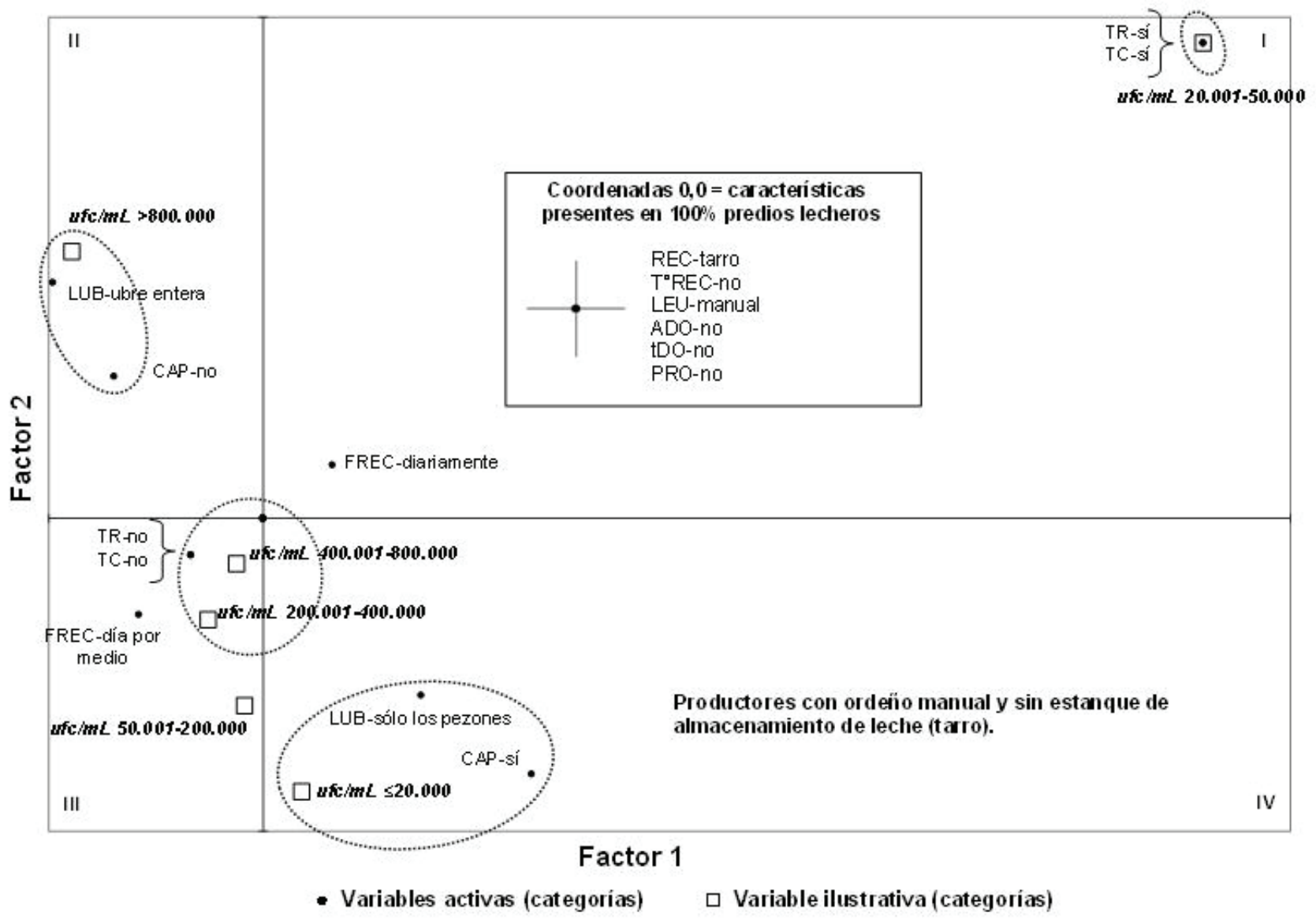

Figura 4. Análisis de correspondencias múltiples, primer plano factorial SP4.

Multiple Correspondence Analysis, first factorial plane Group SP4.

$\mathrm{REC}=$ Forma recolección; $\mathrm{T}^{\circ} \mathrm{REC}=\mathrm{T}^{\circ}$ recolección $4-6{ }^{\circ} \mathrm{C} ; \mathrm{FREC}=$ Frecuencia recolección; $\mathrm{LEU}=$ Limpieza de equipos/utensilios de ordeño; $\mathrm{ADO}$ $=$ Empleo agua caliente $\left(70-75^{\circ} \mathrm{C}\right)$ en lavado equipos/utensilios de ordeño con detergente alcalino clorado; $\mathrm{tDO}=$ Lavado equipos/utensilios de ordeño con detergente alcalino clorado es entre 8 - 10 min.; LUB = Lavado de ubres; TR = Tarros en rejillas o colgados boca abajo, sobre el nivel del suelo; TC = Se filtra la leche en los tarros; $\mathrm{PRO}=$ Protocolos para lavado de equipos de ordeño, utensilios y/o estanque; $\mathrm{CAP}=\mathrm{Capacitación} \mathrm{ordeñador} \mathrm{(último} \mathrm{año).}$

empleaba agua a la temperatura recomendada ni respetaba los tiempos asignados (tDO) a un lavado ideal $\left(70-75^{\circ} \mathrm{C}\right.$ durante 10 minutos) cuando se utiliza detergente alcalino clorado (ADO), además, ningún predio disponía de protocolos para tal efecto (PRO).

\section{DISCUSIÓN}

\section{SISTEMA PRODUCTIVO 1 (SP1)}

Las características del SP1 pueden ser asociadas principalmente a las adecuadas formas de manejo a nivel predial. Pérez (2011), encontró que los sistemas productivos más intensivos, por tener procedimientos de ordeño más eficaces, pueden producir leche de mejor calidad microbiológica, como ocurre en este caso, en especial si se comparan sus resultados con los de los grupos SP3 y SP4, como se indica más adelante.
La adecuada limpieza (temperatura de lavado $70-75^{\circ} \mathrm{C}$ $/ 10$ minutos) de equipos de ordeño y estanque de frío se avalan por el uso correcto de protocolos de lavado (PRO igual a 80\%) y la capacitación de ordeñadores (CAP igual a $85 \%$ ), como práctica común. Según Reinemann y col (2003) y Martins y col (2008), con una adecuada limpieza se pueden conseguir recuentos bacterianos en la leche $\leq 20.000 \mathrm{ufc} / \mathrm{mL}$. Además, se observó que las pezoneras (PEZ-no igual a 98\%) se encontraban en buen estado (no rugosas ni rotas), debido a un reemplazo periódico de éstas, lo que obviamente facilitó su limpieza, coincidiendo con lo señalado por Hillerton y col (2004), quienes indican que las pezoneras y piezas de goma en buen estado facilitan su limpieza e higienización.

Llamó la atención que en los predios del SP1, un porcentaje importante de ellos no realizaban el lavado de los pezones durante la rutina de ordeño (LUB igual a 54\%), práctica de manejo recomendada por Wattiaux (2005). 
Sin embargo, se observó que en la mayoría de éstos se habían eliminados los pelos de la ubre de las vacas, las que se encontraban limpias. Al respecto, Elmoslemany y col (2009) y Halbedl (2009), reportaron una asociación significativa entre bajos recuentos bacterianos de la leche y la eliminación de pelos de la ubre lo que facilita el lavado de ésta, lo que explicaría en parte los resultados del estudio en este grupo de predios.

\section{SISTEMA PRODUCTIVO 2 (SP2)}

Llama la atención que en este grupo de predios en la mayoría de los casos las formas de manejo y obtención de leche no eran adecuadas, pese a lo cual los recuentos bacterianos fueron bajos $(<20.000 \mathrm{ufc} / \mathrm{mL})$ y permitieron a estos productores alcanzar la máxima bonificación que por este concepto entrega la industria. Dentro de las formas de manejo inadecuadas e importantes se puede señalar que, por ejemplo, la temperatura de lavado de los equipos y estanque de ordeña en la mayoría de estos predios no superó los $60^{\circ} \mathrm{C}$, debiendo alcanzar entre los 70 y $75^{\circ} \mathrm{C}$, y el tiempo de lavado de estos no superaba los 5 minutos, debiendo ser de 10 minutos como mínimo; lo que se vio reflejado en líneas y mangueras de leche, unidad final (vaso de leche) e equipos en general con restos de grasa y sucios, factores predisponentes para el desarrollo y multiplicación de bacterias.

Contrariamente a lo que señalan diversos estudios, en que se indica que este manejo inadecuado habitualmente se correlaciona con altos recuentos bacterianos en la leche (Wazna-Zwierzyn'ska 2006, Elmoslemany y col 2009, Bava y col 2009, Halbedl 2009 y Elmoslemany y col 2010), en el presente estudio estuvo asociado a recuentos $\leq 20.000 \mathrm{ufc} / \mathrm{mL}$ (figura 2), recuentos que le permitió a estos productores alcanzar la máxima bonificación que entrega la industria por este concepto. Esta inconsistencia tendría su explicación en el hecho que, en un porcentaje importante de estos predios se empleaban "altas dosis" de un sanitizante en base a ácido acético + peróxido de hidrógeno en la desinfección de equipos y estanques de frío, el que era utilizado 20 a 30 minutos antes de iniciar el ordeño. El uso excesivo de este tipo de sanitizante podría generar residuos de peróxido de hidrógeno que podrían quedar retenidos en los equipos, y que en contacto con la leche además de producir un fuerte efecto bactericida y bacteriostático (activación sistema lactoperoxidasa), puede generar también efectos negativos en ésta de acuerdo a lo señalado por Hovinen y col (2004), FAO (2005) y Martins y col (2008).

\section{SISTEMA PRODUCTIVO 3 (SP3)}

La limpieza de los equipos de ordeño en forma manual y el no cumplimiento del tiempo de lavado en la mayoría de los predios, probablemente tuvo como consecuencia que en un alto porcentaje de éstos (62\%) las mangueras de leche (LML) se encontraban sucias, situación que según Keown y Kononoff (2006) se encuentra asociada a altos recuentos bacterianos. Además, el excesivo tiempo de uso de las pezoneras, reflejado en un mal estado (PEZ = rugosas y rotas), también constituye uno de los factores asociados con frecuencia a una mayor contaminación y multiplicación de las bacterias (Koning y col 2004) y Halbedl 2009).

La recolección de leche en tarros llevada a cabo por el grupo SP3 también puede afectar negativamente la calidad microbiológica, de acuerdo a lo señalado por Revelli y col (2004), Keown y Kononoff (2006) y Kongo y col (2009), ya que este medio de almacenamiento y transporte de la leche es un factor predisponente para el incremento y desarrollo las bacterias.

Algunos productores (cuadrantes I-IV) con características como el vaso de leche limpio (VAS), y que emplean el tiempo adecuado de lavado con detergente alcalino clorado y con solución ácida (tDO, tRO), fueron capaces de obtener recuentos de 20.001-50.000 ufc/mL. Aquellos productores (cuadrante IV) que aplican un sistema automatizado de lavado (LEU), que cumplen con los requisitos recomendados de temperatura inicial del agua $(\mathrm{ADO})$ y transcurridos 8-10 min $\left(\mathrm{T}^{\circ} \mathrm{SO}\right)$ con detergente alcalino clorado, y posterior lavado ácido de acuerdo a la temperatura recomendada (LAO), son capaces, igualmente, de alcanzar recuentos sujetos a bonificación (50.0001-200.000 ufc/mL).

\section{SISTEMA PRODUCTIVO 4 (SP4)}

Al igual que el SP3, el nivel tecnológico del SP4 lo considera como un "grupo problema". Según Keown y Kononoff (2006), todas las características negativas del lavado de los tarros empleados en la ordeña se asocian a altos recuentos bacterianos.

El manejo de los tarros era deficiente, ya que mayoritariamente eran mantenidos boca abajo, en contacto directo con el suelo (TR 93\%), además, no se aplicaba ningún tipo de "filtrado" de la leche vaciada en éstos (TC 93\%), pudiendo constituir un foco de contaminación, medidas que según González (2003) y Wattiaux (2005), habitualmente se asocian a altos recuentos bacterianos, y, por lo cual que en este caso estuvieron sujetos a descuentos económicos (200.001-400.000y 400.001-800.000 ufc/mL).

En este grupo se observó que los recuentos bacterianos más altos (> $800.000 \mathrm{ufc} / \mathrm{mL}$ ) se presentaron mayoritariamente en aquellos predios donde los ordeñadores no han sido capacitados (CAP) durante el último año, y además realizaban un lavado inadecuado de los pezones (LUB-completa) (cuadrante II), es decir, se lavaba toda la ubre quedando restos de agua escurriendo en éstos y no se utilizaba una toalla de papel desechable para secarlos, lo que según Wattiaux (2005) está asociado a altos recuentos bacterianos en la leche. Contrario a lo anterior y de acuerdo a lo que aparece en la figura 4 (cuadrante IV), 
en algunos predios donde los ordeñadores han sido capacitados (CAP), y donde éstos realizan un lavado y secado adecuado de los pezones, es decir, lavado sólo de éstos y secado individual con toalla de papel desechable (LUBsólo el pezón), la leche puede alcanzar excelentes recuentos $(\leq 20.000 \mathrm{ufc} / \mathrm{mL})$.

Finalmente, de acuerdo a los antecedentes obtenidos en el presente estudio, se puede concluir que la mayor parte de la leche producida a nivel predial en este grupo de productores, clasificó dentro del mejor rango de calidad microbiológica ( $\leq 20.000 \mathrm{ufc} / \mathrm{mL}$ ), aportada mayoritariamente por el grupo SP1 (87\%), producto de adecuadas formas de manejo y obtención de leche a nivel predial. Sin embargo, en el caso del grupo SP2 los bajos recuentos bacterianos presentes en su leche podrían estar relacionados con el uso excesivo y, por lo tanto, con el efecto residual de sanitizantes en el lavado de equipos; surge entonces la necesidad de analizar con mayor profundidad dicho comportamiento. En el caso de los grupos SP3 y SP4 que se caracterizaron principalmente por producir leche de "mala calidad" desde el punto de vista microbiológico (> $200.000 \mathrm{ufc} / \mathrm{mL}$ ), si bien aportaron sólo un 3\% del total de la leche de la muestra de productores estudiada, constituyen un $37 \%$ de la población total de productores que abastecen a esa industria. Debido a esto, existe una gran cantidad de ellos que pueden ver limitadas sus posibilidades de desarrollo al producir leche fundamentalmente sujeta a descuentos económicos, por lo cual es urgente poder determinar y aplicar medidas orientadas a mejorar la calidad de la leche.

\section{REFERENCIAS}

Avilez J, P Escobar, G von Fabeck, K Villagrán, F García, R Matamoros, A García. 2010. Caracterización productiva de explotaciones lecheras empleando metodología de análisis multivariado. Rev Cient FCV-LUZ 20, 74-80.

Ayadi M, G Caja, X Such, C Knight. 2003. Effect of omitting one milking weekly on lactational performances and morphological udder changes in dairy cows. J Dairy Sci 86, 2352-2358.

Bava L, M Zucali, M Brasca, L Zanini, A Sandrucci. 2009. Efficiency of cleaning procedure of milking equipment and bacterial quality of milk. Ital J Anim Sci 8, 387-389.

Bécue M. 2002. Manual de introducción a los métodos factoriales y clasificación con SPAD. Servei d'Estadística, Universitat Autónoma de Barcelona, Barcelona, España.

Berenson M, D Levine. 1992. Estadística básica en administración. Conceptos y aplicaciones. Prentice -Hall Hispanoamericano S. A., México DF, México.

Carrillo B, C Vidal. 2002. Los esquemas de pago de leche en Chile. En: Curso Gestión Económica de la Producción Lechera. Centro de Economía Rural de Frutillar (CER) y Fundación Chile, Puerto Varas, Chile, Pp 1-14.

Elmoslemany A, G Keefe, I Dohoo, B Jayarao. 2009. Risk factors for bacteriological quality of bulk tank milk in Prince Edward Island dairy herds. Part 1: Overall risk factors. $J$ Dairy Sci 92, 2634-2643.
Elmoslemany A, G Keefe, I Dohoo, J Witchel, H Stryhn, R Dingwell. 2010. The association between bulk tank milk analysis for raw milk quality and on-farm management practices. J Prev Vet Med 95, 32-40.

Escofier B, J Pages. 1992. Análisis factoriales simples y múltiples: objetivos, métodos e interpretación. Ed. Universidad del país Vasco, Bilbao, España.

FAO, Food and Agriculture Organization of the United Nations. 2005. Beneficios y riesgos potenciales del sistema lactoperoxidasa en la conservación de la leche cruda. Informe de la reunión técnica 28 noviembre - 2 diciembre. FAO Roma, Italia.

Garnica E. 1988. Una imagen aplicación del análisis estadístico de correspondencias múltiples. Facultad de Ciencias Económicas y Sociales. Universidad de los Andes. Mérida, Venezuela. Rev Econ 2, 1-21.

Godic K, S Golc. 2008. The microbiological quality of raw milk after introducing the two day's milk collecting system. Acta Agr Slov 92, 61-74.

González M. 2003. Factores determinantes de la calidad higiénica de la leche de pequeños productores en tres Centros de Acopio de la provincia de Valdivia. Universidad Austral de Chile. Tesis Lic. en Ciencias de los Alimentos, Facultad de Ciencias Agrarias, Universidad Austral de Chile, Valdivia, Chile.

Hair J, R Anderson, R Tatham, W Black.1999. Análisis multivariante. $5^{\mathrm{a}}$ ed. Prentice Hall, Madrid, España.

Halbedl N. 2009. Efficacy of teat cleaning in automatic milking systems (AMS) and effects of hygiene management on teat cleanliness. Faculty of Medicine Veterinary, University of Berlin, Berlin, Germany.

Hernández R, R Fernández, C Fernández, P Baptista. 1998. Metodología de la investigación. Editorial Mc Graw - Hill. México.

Hillerton E, D Boast, I Ohnstand. 2004. Changes in milking liner performance with age. Bulletin of International Dairy Federation 388, 35-40.

Hoe F, P Ruegg. 2006. Opinions and practices of Wisconsin dairy producers bout biosecurity and animal well-being. $J$ Dairy Sci 89, 2297-2308.

Hovinen M, A Aisla, S Pyo. 2005. Visual detection of technical success and effectiveness of teat cleaning in two automatic milking systems J Dairy Sci 88, 3354-3362.

Keown J, P Kononoff. 2006. Producing milk with a low bacteria count. Institute of Agriculture and Natural Resources, University of Nebraska, Lincoln, USA.

Kongo J, A Gomes, X Malcata. 2009. Characterization of hygiene practices and microbiology of raw milk in São Jorge dairy farms. Egypt J Dairy Sci 37, 125-138.

Koning K, O Ronningen, M Bjerring, B Ipenma. 2004. Testing of liner and measuring material properties. Bulletin of International Dairy Federation 388, 58-64.

Martins M, E Nicolau, A Mesquita, R Neves, M Arruda. 2008. Raw quality of milk produced and stored in bulk tanks in Goias State, Brazil. Cienc Anim Bras 9, 1152-1158.

Mattos, M, V Beloti, R Tamainini, D Magnani, L Nero, M Barros, E Pires. 2010. Quality of raw milk produced in agreste region Pernambuco, Brazil. Semin-Cienc Agrar 31, 173-182.

Pérez J. 2011. Sistemas productivos, parámetros técnicos y calidad de leche bovina de productores del sur de Chile. Cien 
Inv Agr 38, 15-29.

Pinargote C. 2009. Evaluación de los recuentos microbiológicos de la leche en predios con distintos sistemas de manejo. Identificación de puntos de control y sugerencia de acciones correctivas. Universidad Austral de Chile. Tesis Magíster en Ciencia y Tecnología de la Leche, Facultad de Ciencias Agrarias, Universidad Austral de Chile, Valdivia, Chile.

Rasmussen M, M Bjerring, P Justesen, L Jepsen. 2002. Milk quality on Danish farms with automatic milking systems. J Dairy Sci 85, 2869-2878.

Reinemann D, G Mein, M Rasmussen, P Ruegg. 2005. Evaluating milking performance. Bulletin of International Dairy Federation 396, 1-24.

Revelli G, O Sbodio, E Tercer. 2004. Recuento de bacterias to- tales en leche cruda de tambos que caracterizan la zona noroeste de Santa Fe y sur de Santiago del Estero. Rev Argent Microbiol 36, 145-149.

Stull C, B Reed, S Berry. 2005. A comparison of three animal welfare assessment programs on California dairies. $J$ Dairy Sci 88, 1595-1600.

Vivanco M. 1999. Análisis estadístico multivariable. Teoría y práctica. Ed. Universitaria, Santiago, Chile.

Wattiaux M. 2005. Dairy essentials: mastitis, prevention and detection. Babcock Institute for International Dairy Research and Development. University of Wisconsin-Madison, Wisconsin, USA, Pp 93-96.

Wazna-Zwierzyn'ska G. 2006. Milk quality as affected by the technical state of milking, milk cooling and transport equipment. J Prace Naukowe 1, 81-100. 